\title{
Understanding the Surfaces and Crystal Growth of Pyrite $\mathrm{FeS}_{2}$
}

\author{
Corinne Arrouvel ${ }^{a, b *}$, Jean-Guillaume Eon $^{b}$
}

\author{
${ }^{a}$ Centro de Ciências e Tecnologias para Sustentabilidade, Departamento de Física, Química e \\ Matemática, Universidade Federal de São Carlos, Campus Sorocaba, Rodovia João Leme dos Santos \\ (SP-264), Km 110, Bairro do Itinga, 18052-780, Sorocaba, SP, Brasil \\ ${ }^{b}$ Instituto de Química, Universidade Federal do Rio de Janeiro, Avenida Athos da Silveira Ramos, 149 \\ Bloco A, Cidade Universitária, 21941-909, Rio de Janeiro, RJ, Brasil
}

Received: December 24, 2017; Revised: May 06, 2018; Accepted: October 02, 2018

\begin{abstract}
Pyrite is a common sulfide mineral, which has arisen early interest by its euhedral shape and by its metallic glow similar to gold. However, it is only in our century that we began to understand pyrite crystal growth, considering the thermodynamic and kinetic aspects of crystal formation as a function of temperature and concentration of the elements present in the medium. This article reports an analysis by molecular mechanics of 11 surfaces associated to observed morphologies in order to explain the growth of natural and synthesized minerals. The lowest surface and attachment energies (respectively $1.04 \mathrm{~J} / \mathrm{m}^{2}$ and $-20.3 \mathrm{~kJ} / \mathrm{mol}$ ) were obtained for the (001) plane, indicating that it is the most stable surface and that kinetic growth also preferentially occurs on this plane. Less known properties, such as crystal striations along the $<100>$ directions, are also discussed.
\end{abstract}

Keywords: force field, pyritohedron, striation, morphology, surface.

\section{Introduction}

Pyrite $\mathrm{FeS}_{2}$ is the most common natural sulfide mineral and has always attracted the interest of humankind. The spark created when a crystal hits other harder material is probably at the origin of the name, pyr, meaning fire in Greek. Welldefined shapes, triangular, cubic or pentagonal facets, with their symbolic appeal, and the golden metallic aspect explain their power of fascination. The stone called fool's gold led several gold prospectors to bankruptcy. Ancient civilizations, like the Maya, used pyrite as an ornament. This sulfide has also been used in Chinese medicine and has industrial applications in the field of catalysis (coal liquefaction), photocatalysis, energy materials such as rechargeable sodium/lithium batteries and solar cells ${ }^{1-8}$. Pyrite is also part of the biomineralization cycle of some organisms, such as magnetotactic bacteria living in a sulfurous environment ${ }^{9,10}$. It may have played as well a significant role in the origin of life ${ }^{11,12}$. The mineral has very common elements, Fe and $\mathrm{S}$, with no commercial value of its own. However, the stone is present in the mineral markets. In fact, pyrite is commonly found in mines during the extraction of coal or various metals. This unfortunately causes environmental problems during the drainage processes of the rocks where the dissolved pyrite participates in the acidification of the rivers ${ }^{13,14}$. The affinity of pyrite for metals was always seen negatively, because it made difficult the extraction of the most precious metals. But today, this affinity is being explored, using pyrite to extract metals from electronic waste ${ }^{15}$.

*e-mail: corinne@ufscar.br
In the case of volcanic, sedimentary or metamorphic minerals containing pyrite or of materials synthesized in the laboratory, pyrite crystals are known to have different morphologies with specific facets, i.e. cubic, octahedral, dodecahedral crystals with pentagonal faces, or shapes combining different facets such as cube modified by octahedron. It is known that the growth of minerals is a function of the conditions of the medium, such as the temperature and acidity of the solution, the relative concentrations of the solutes in the liquid phase, most importantly the supersaturation degree of iron and sulfur solutes and partial pressures of the gases above the solution. The various exposed facets are generally well defined and show kinetic growth which vary according to these conditions.

This article discusses some models optimized with molecular mechanics to explain different observed morphologies. It aims to bring new insights on thermodynamic and kinetic growth to clarify the observed morphologies and striations on surfaces. It is organized as follows. The next section introduces the theoretical methodology used to simulate pyrite surfaces and morphologies. Section 3 is devoted to the description of morphologies of the different pyrite minerals and the calculation of exposed surfaces. The theoretical results are then discussed in section 4 , analyzing the experimental data in light of the existing theories.

\section{Methodology}

The focus of this study was the understanding of the forms of pyrite crystals as a function of thermodynamic and kinetic conditions. For that, surface energies (thermodynamics) and 


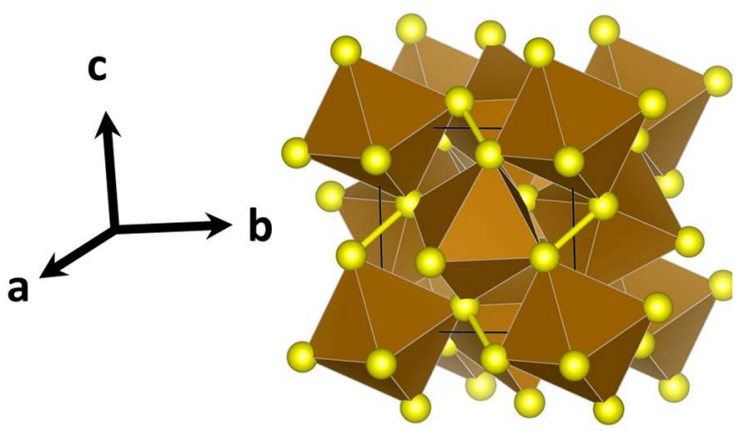

Figure 1. Crystal structure of pyrite $\left(\beta-\mathrm{FeS}_{2}\right){ }^{17}(\mathrm{Fe}$ in the center of the octahedron, S: yellow spheres).

attachment energies (kinetics) of pyrite were estimated. In this section, we present the classic method based on Born ${ }^{16}$ model for the study of pyrite. Pyrite belongs to the cubic system; the unit cell, seen in Figure 1, contains $4 \mathrm{FeS}_{2}$ units. Iron atoms occupy the vertices and center of the faces in the unit cell. The iron ion has coordination number 6 (i.e. six sulfur atoms) and the sulfur ion a coordination of 4 (three $\mathrm{Fe}$ atoms and one sulfur). Iron atoms and $\mathrm{S}_{2}{ }^{2-}$ dimers occupy FCC (face centered cubic) sites forming a NaCl-like structure. The pyrite space group is $\mathrm{P} a 3$.

The classic simulations were done using the program METADISE ${ }^{18}$ (Minimum Energy Techniques Applied to Dislocation, Interface, and Surface Energies). Various surface terminations are created automatically using the Tasker ${ }^{19}$ approach. The reader will find a broader description of the methodology in the work of de Leeuw et al..$^{20}$ We have used the same methodology with the same potentials in the present work, calculating $11\{\mathrm{hkl}\}$ surfaces. The interatomic potential was then built by adding Coulomb interactions and Buckingham potential according to the relation:

$V_{r_{i j}}=\sum \frac{1}{4 \pi \varepsilon_{0}} \frac{q_{i} q_{j}}{r_{i j}}+A_{i j} \exp \left(-r_{i j} / \rho_{i j}\right)-\frac{C_{i j}}{r_{i j}^{6}}$

where $q_{i}$ and $q_{j}$ represent the charge of each ion, $r_{i j}$ the distance between the ions and $\mathrm{A}_{\mathrm{ij}}, \rho_{\mathrm{ij}}, \mathrm{C}_{\mathrm{ij}}$ are ion-ion parameters in the Buckingham relation. We applied a cutoff of $20 \AA$ in the simulation for short-range interactions. The $\mathrm{S}_{2}$ dimer was also defined by introducing a mathematical harmonic function $\phi$ (equation [2]) with a constant force $k_{i j}$.

$$
\phi_{i j}\left(r_{i j}\right)=\frac{1}{2} k_{i j}\left(r_{i j}-r_{0}\right)^{2}
$$

where $r_{0}$ represents the separation between the two atoms at equilibrium.

Analogously, an angular interaction, 3-body S-S-Fe term was introduced:

$$
\phi_{i j k}\left(r_{i j k}\right)=\frac{1}{2} k_{i j k}\left(\theta_{i j k}-\theta_{0}\right)^{2}
$$

Table 1. Interatomic potentials for $\mathrm{FeS}_{2}$

\begin{tabular}{lccc}
\hline $\mathrm{q}(|\mathrm{e}|)$ & $\mathrm{Fe}+2.0$ & \multicolumn{2}{c}{$\mathrm{S}-1.0$} \\
\hline Buckingham potentials & $\mathrm{A}(\mathrm{eV})$ & $\mathrm{r}(\AA)$ & $\mathrm{C}\left(\mathrm{eV} / \AA^{6}\right)$ \\
Fe-S & 94813.90 & 0.18125 & 0.0000 \\
$\mathrm{~S}-\mathrm{S}$ & 1777.08 & 0.33080 & 97.4915 \\
Constant Force & $\mathrm{k}(\mathrm{eV})$ & $\mathrm{r}_{0}(\AA)$ & \\
S-S & 8.44 & 2.23 & \\
3-body potential & $\mathrm{k}\left(\mathrm{eV} \mathrm{rad}^{-2}\right)$ & $\mathrm{Q}_{0}$ & \\
$\mathrm{~S}-\mathrm{S}-\mathrm{Fe}$ & 12.5 & 109.503 & \\
\hline
\end{tabular}

The parameters of the interatomic potentials are listed in Table 1; the validity of these potentials was confirmed by comparison of the simulated values with experimental data $^{17,21,22}$ (elastic constant, structural parameters, etc.).

The surface energy in vacuum, $\boldsymbol{\gamma}_{h k l}$, for the (hkl) surface of the crystal, can be calculated from the following expression:

$$
\gamma_{h k l}=\frac{E_{h k l}-N \cdot E_{b u l k}}{A_{h k l}}
$$

where $E_{h k 1}$ stands for the energy of the (hkl) surface, $\mathrm{E}_{\text {bulk }}$ represents the energy of the bulk normalized to the number $\mathrm{N}$ of $\mathrm{FeS}_{2}$ units considered in the supercell and $A_{h k l}$ corresponds to the surface area.

Surface energy is an index of the stability of the surface. The lower the surface energy, the more stable the surface. Therefore, thermodynamically stable surfaces may be inert, while unstable and defective surfaces may favor reactions. Surface reactivity is important in catalysis and corrosion studies.

Attachment energy, following the theory of HartmanPerdok ${ }^{23}$, provides an understanding of the growth of crystals. It corresponds to the energy released per mol by the growth of a layer (or slice) of thickness $d_{\text {hkl }}$ (interplanar distance) which is an exothermic process. The attachment energy is given by the expression:

$$
E_{h k l}^{a t t}=E_{\text {bulk }}-. E_{\text {slice }}
$$

where $E_{\text {bulk }}$ is the lattice energy of the crystal, $E_{\text {slice }}$ is the energy of the slice (hkl) per mol. Surfaces with high attachment energy grow rapidly while the lower surface energies are preferably exposed, thus defining the morphology of the crystal. The morphology of an ideal crystal of fixed volume minimizes the surface energy of the particle. It is constructed using the law of Gibbs-Curie-Wulff ${ }^{24}$.

$$
\frac{M_{h k l}}{h_{h k l}}=\alpha,
$$

where the $\mathrm{M}_{h k l}$ value depends on the type of morphology desired: one uses $\mathrm{M}_{h k l}=\gamma_{h k l}$ to obtain the morphology at thermodynamic equilibrium under vacuum, using surface 
energies, or $\mathrm{M}_{h k l}=\left|E_{h k l}^{a t t}\right|$ to get the morphology under kinetic growth, using attachment energies; $h_{h k l}$ corresponds to the distance from the center of mass of the solid to the (hkl) surface and $\alpha$ is a characteristic constant of the material.

METADISE ${ }^{18}$ software allows to derive the crystal morphology under thermodynamic or kinetic control of the pyrite using the energies extracted by classical methods. The advantage of this technique is that one can model various types of surfaces and generate morphologies using a simple laptop.

The principles underlying the construction of crystalline morphologies can be illustrated simply for the cubic unit cell. The simplest morphology in this case is a hexahedron with square faces, that is: a cube. The surface of the cube is defined by the family of $6\{100\}$ planes, i.e. by the six surfaces. Two morphologies are defined by the family $\{\mathrm{h}$, $\mathrm{k}, 0\}$, with 12 facets in both cases (dodecahedron with parallelogram facets). In the case $\mathrm{h}=\mathrm{k}$ (e.g. $\{110\}$ ), the morphology is a regular dodecahedron; in the case of $\mathrm{h} \neq \mathrm{k}$ (e.g. $\{210\}$ ), an irregular dodecahedron with pseudopentagonal facets is formed. In the simulated morphology, the edge at the intersection between two twins gets a longer distance compared to the other four edges. Finally, in the case of the family $\{h, k, 1\}$ with $h \neq k \neq 1$, one gets 24 facets, corresponding to an icositetrahedron. If $\mathrm{h}=\mathrm{k}=1$, the shape will have 8 facets forming an octahedron with triangular facets. Some simulated morphologies, commonly found in pyrite, are shown in Fig. 2.

\section{Surfaces and Morphologies of Pyrite}

\subsection{Observed morphologies of minerals}

We present three typical forms of pyrite crystals from geological origin: cubic (Fig. 3a), octahedral (Fig. 3b) and pyritohedral (Fig. 3c).

The cubic morphology is frequent in nature but natural minerals are not perfectly cubic and form twins. We observe 3 different lengths along the $\mathrm{a}, \mathrm{b}, \mathrm{c}$ directions, in other word, it is a rectangular prism. Striations are also observed on the crystal surfaces with cubic morphologies (Fig. 3a), always in [100], [010] or [001] directions. The largest crystal in Figure $3 \mathrm{a}$ has a face of dimension $2.0 \mathrm{~cm} \times 1.5 \mathrm{~cm}$.

In the octahedral morphology (Fig. 3b), there are 8 facets from the $\{111\}$ family. There is no striation on plane triangles $\{111\}$. The square base of the crystal is $1.0 \mathrm{~cm}$.

In the pyritohedral pyrite crystals (sizes around half centimeter and below, fig. 4c), there are striations, such as in the cubic case, along [100], [010] or [001] directions. The twin facets (021) and (02-1) (and by complementarity, the twin facets (0-21) and (0-2-1)) have striations oriented along the [100] direction. Striations on twin facets (102)

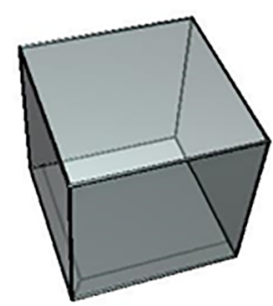

(a)

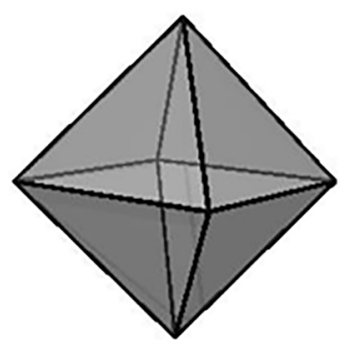

(c)

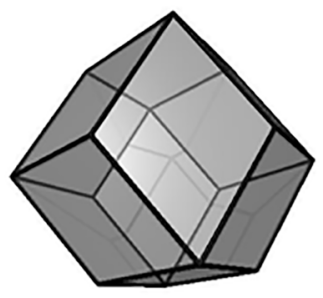

(e)

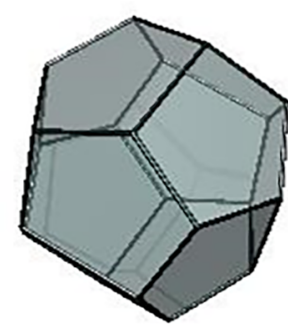

(b)

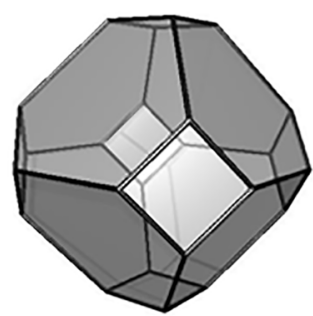

(d)

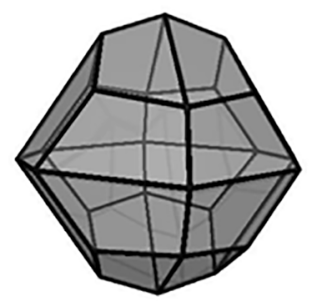

(f)
Figure 2. Morphologies calculated a) with $\{100\}$ cubic hexahedron, b) pyritohedral dodecahedron (with $\{210\})$ c) octahedron ( $\{111\}$ ), d) $\{111\}$ and $\{100\}$ truncated octahedron, e) $\{110\}$ dodecahedron, f) $\{123\}$, icositetrahedron.

and (-102) are along the [010] direction and those on twin facets (2-10) and (210) are along the [001] direction. We can also observe for each twin that one facet is rougher than the other. This pyritohedral morphology with this type of striations is called positive pyrite, a denomination due to Endo and Sunagawa ${ }^{25}$. Figure 5a schematically shows the profile of the lines on the surface family $\{210\}$ of the observed pyritohedral pyrite. The same authors ${ }^{25}$ have also described pyritohedral negative pyrite. The orientation of the striations is symbolized in Figure $5 \mathrm{~b}$. The pentagonal facets of the natural mineral (Fig. 4c) are distorted.

Other forms of pyrite may be observed for example with a combination of these facets with truncated corners (such as truncated cube, truncated octahedron, truncated dodecahedron) and / or appearance of other facets (such as $\{310\},\{410\}$ and $\{320\})^{26}$.

\subsection{Calculated surfaces}




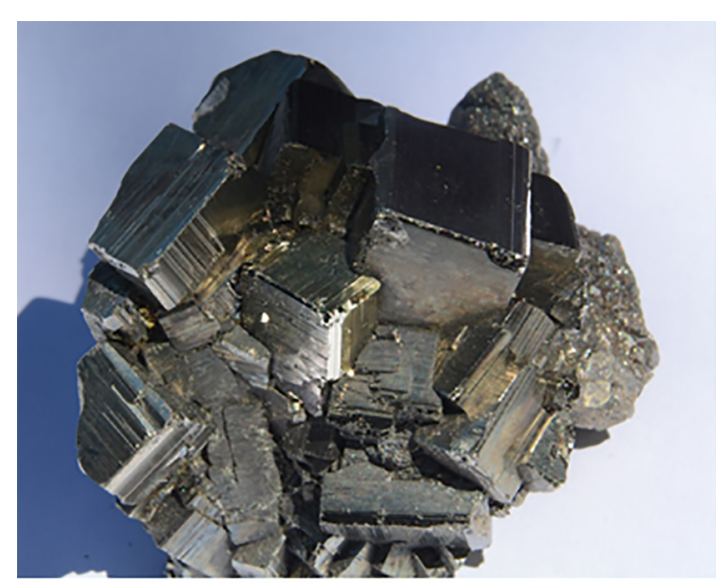

(a)

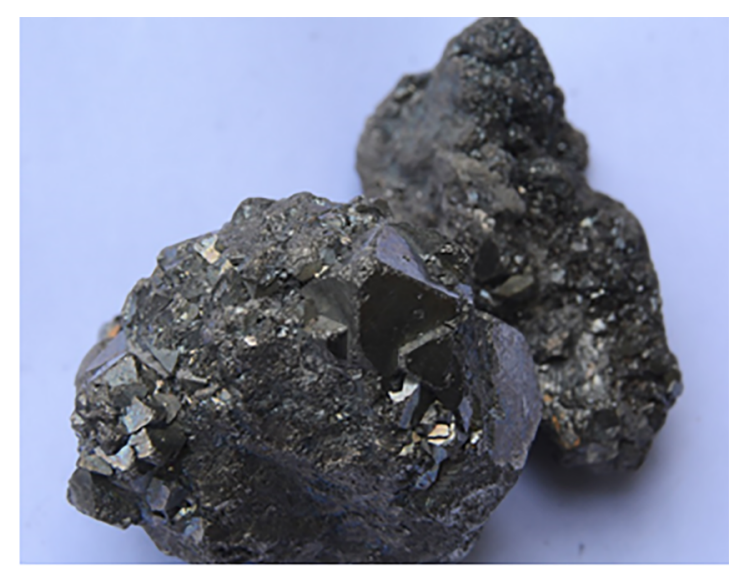

(b)

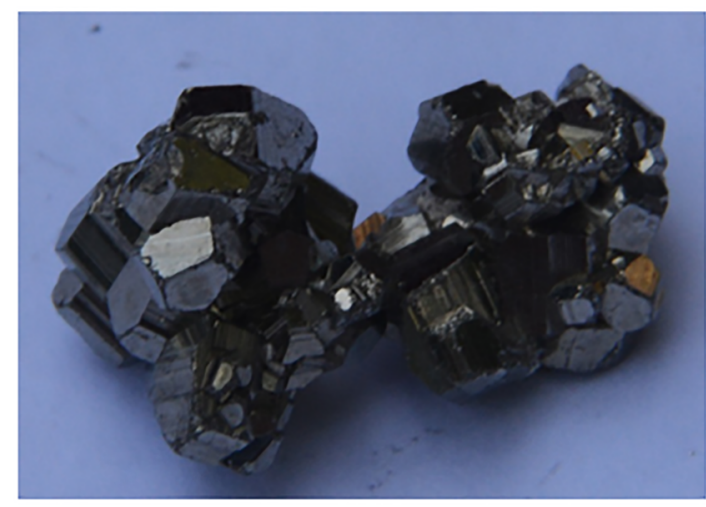

(c)

Figure 3. Crystals of pyrite with a) cubic morphology ( $\{100\})$ (C. Arrouvel), b) octahedral ( $\{111\})$ museum donation Urca, Rio de Janeiro c) pyritohedral ( $\{210\})$ (C. Arrouvel, origin Peru).

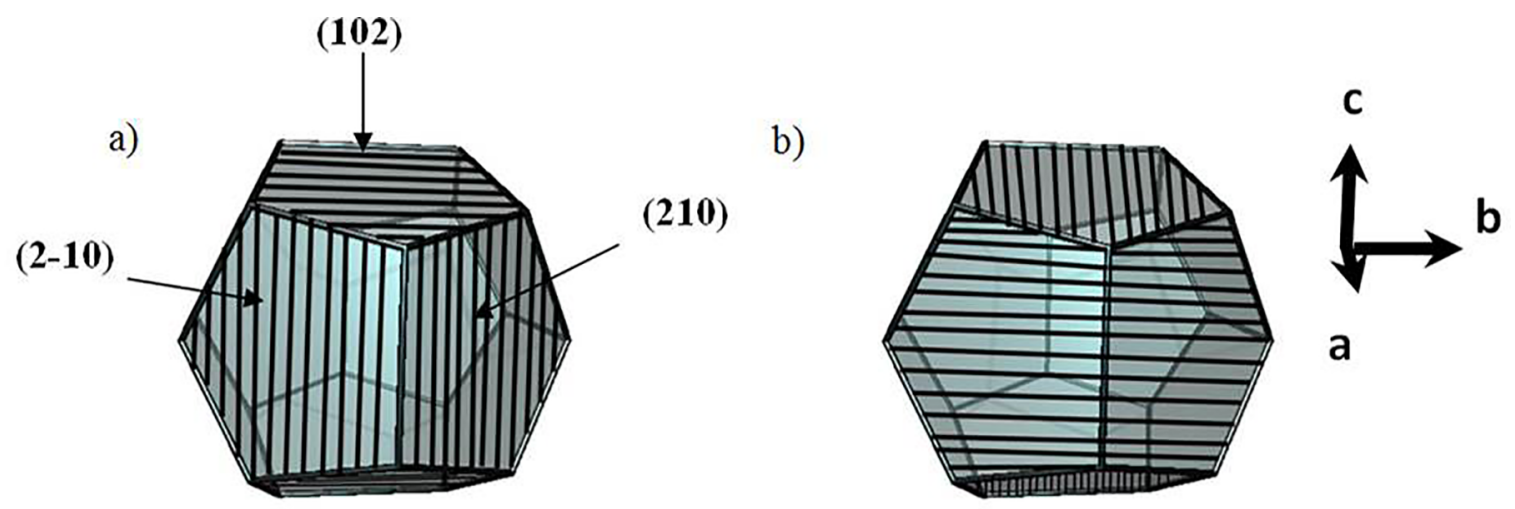

Figure 4. Pyritohedral pyrite (dodecahedron with pentagonal facets) a) positive; b) negative.

The most common facets were calculated using METADISE in order to evaluate the structure, stability of each surface and deduce the morphology of the crystal. The classical methods allow calculating a higher number of surface types with higher Miller indices (see Table 2). The order of stability using classical potentials given in Table 1 is:
$(001)<(310)<(210)<(320)<(110)<(540)<(311)$ $<(430)<(211)<(410)<(111)-\mathrm{Fe}$.

Lower energy surfaces, as given after relaxation are the most stable. The most stable surface is thus the surface (001) giving a cubic morphology when pure. The other stable 


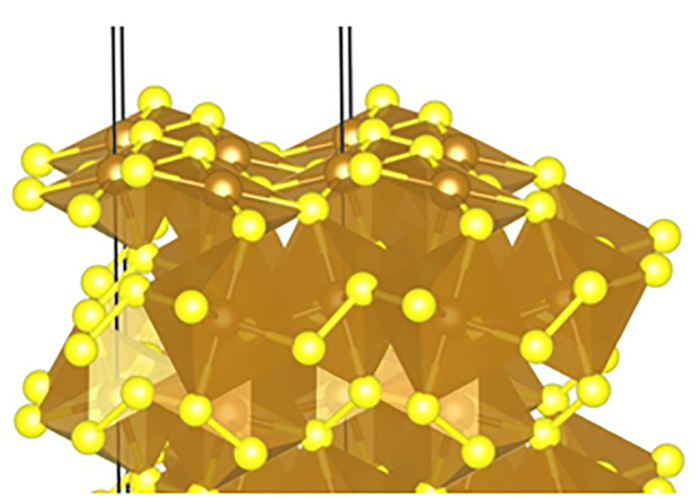

(a)

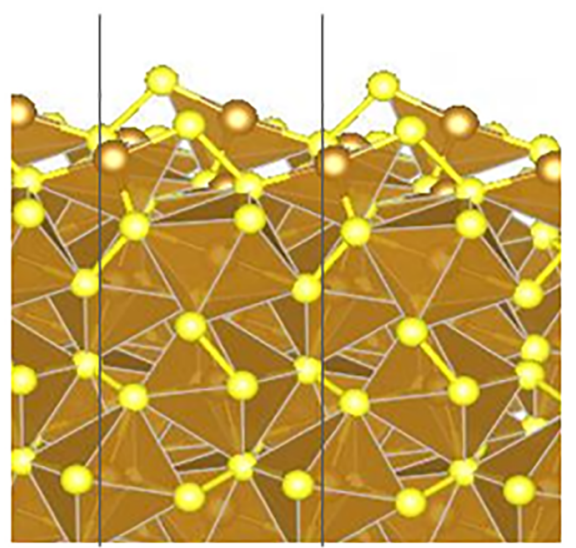

(c)

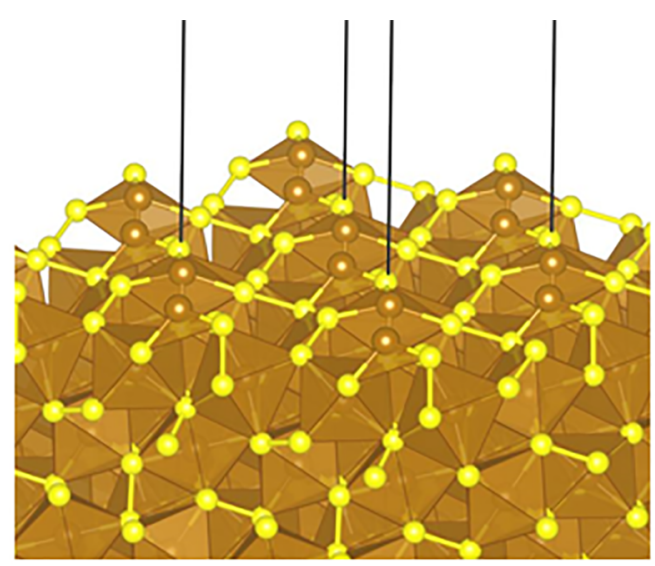

(b)

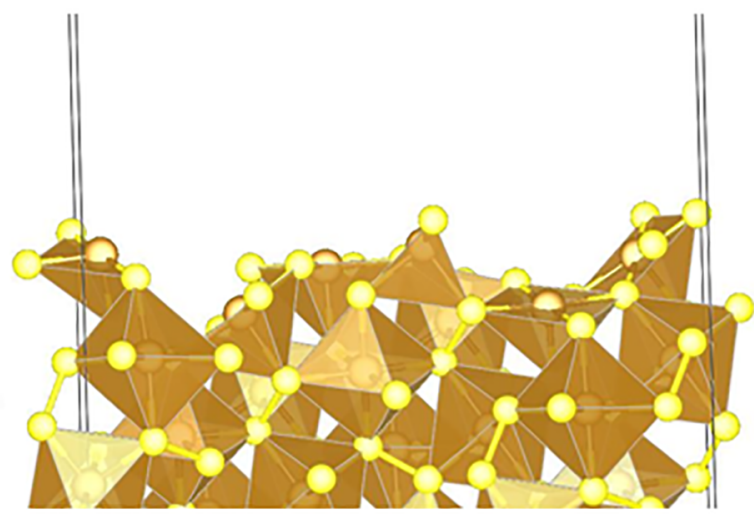

(d)

Figure 5. Polyhedral representation of surfaces (optimized using force field) a) (100), b) (111), c) (210), d) (310).

Table 2. Surface energy and structure of the facets of Miller indices $\{\mathrm{hkl}\}$.

\begin{tabular}{lccccccc}
\hline Indexes & $\mathrm{d}_{\mathrm{hkl}}(\AA)$ & $\begin{array}{c}\text { Attachment } \\
\text { energy } \\
(\mathrm{eV})\end{array}$ & $\begin{array}{c}\text { Surface energy } \\
\text { unrelaxed } \\
\left(\gamma_{\mathrm{hk}}\right)\left(\mathrm{Jm}^{-2}\right)\end{array}$ & $\begin{array}{c}\text { Surface energy } \\
\text { relaxed } \\
\left(\gamma_{\mathrm{hk}}\right)\left(\mathrm{Jm}^{-2}\right)\end{array}$ & Termination & $\begin{array}{c}\text { Coverage Fe } \\
\left(\text { atom } / \mathrm{nm}^{2}\right)\end{array}$ & $\begin{array}{c}\text { Coverage S } \\
\left(\text { atom/ } \mathrm{nm}^{2}\right)\end{array}$ \\
\hline$(001) \mathrm{S}$ & 1.82 & 0.21 & 1.29 & 1.04 & $\mathrm{~S} 1 \mathrm{~S} 2$ & 6.7 & 6.7 \\
$(001) \mathrm{Fe}$ & 1.82 & 5.65 & 5.87 & 4.67 & $\mathrm{Fe}$ & 3.3 & 6.7 \\
$(110)$ & 3.87 & 0.50 & 2.48 & 1.97 & $\mathrm{~S} 1 \mathrm{~S} 2$ & 4.7 & 9.4 \\
$(111) \mathrm{Fe}$ & 3.16 & 1.31 & 4.78 & 3.22 & $\mathrm{Fe}$ & 3.8 & 11.5 \\
$(111) \mathrm{S}$ & 3.16 & 1.31 & 4.89 & 3.38 & $\mathrm{~S} 1 \mathrm{~S} 2$ & 7.7 & 7.7 \\
$(210)$ & 2.45 & 0.62 & 2.11 & 1.65 & $\mathrm{~S} 1 \mathrm{~S} 2$ & 6.0 & 8.9 \\
$(211)$ & 2.24 & 1.38 & 3.65 & 2.62 & $\mathrm{~S} 1 \mathrm{~S} 2$ & 6.8 & 8.2 \\
$(310)$ & 1.73 & 0.70 & 1.90 & 1.47 & $\mathrm{Fe} \mathrm{S}$ S2 & 6.3 & 7.4 \\
$(311)$ & 1.65 & 1.47 & 3.06 & 2.25 & $\mathrm{~S} 1 \mathrm{~S} 2$ & 6.0 & 8.0 \\
$(320)$ & 1.52 & 1.14 & 2.28 & 1.79 & $\mathrm{~S} 1 \mathrm{~S} 2$ & 5.5 & 8.3 \\
$(410)$ & 1.33 & 1.94 & 3.33 & 2.86 & $\mathrm{~S} 1 \mathrm{~S} 2$ & 6.5 & 7.3 \\
$(430)$ & 1.10 & 3.75 & 5.10 & 2.34 & $\mathrm{~S} 1 \mathrm{~S} 2$ & 6.0 & 9.3 \\
$(540)$ & 0.86 & 3.74 & 4.52 & 2.22 & $\mathrm{Fe} \mathrm{S} 1 \mathrm{~S} 2$ & 6.2 & 8.8 \\
\hline
\end{tabular}

$\mathrm{d}_{\mathrm{hkl}}:$ interplanar distances 
surfaces belong to the pyritohedral morphologies, such as those observed in the Hispanic mines Cameros ${ }^{26}$.

Surface energies calculated according to classical and quantum methods, reported in Table 3, agree in relation to the order of stability of the surfaces. Some differences appear between the results from $a b$ initio calculations reported by Hung et al. ${ }^{27,28}$ and those given by Alfonso ${ }^{29}$ (Table 3) but they may be due to the different thickness choices of surfaces, cutoff energies, k-points grid in the Brillouin zone, stoichiometric versus non-stoichiometric models. Using force field methods, we found that the (210) surface is more stable than the stoichiometric (111) surface, a result that cannot be compared with quantum results described by Alfonso ${ }^{29}$. Indeed, in the latter case, the modeled (111) surfaces contain sulfur in excess which results in stabilization of the surface, according to calculations applying the chemical potential approach; the surface energy of the stoichiometric surface is not given by the author. The optimized stoichiometric surfaces are represented in Figure 5.

Assuming the above surface energies calculated with interatomic potentials, one may tentatively explain the observed morphology of the crystal. Considering first a growth in vacuum involving all surfaces, the cubic growth dominates. The two other typical shapes are possible with a strong stabilization of the $\{210\}$ and $\{111\}$ facets respectively. However, the relative stabilization of each surface depends on partial pressures and temperature. We delay the respective discussion concerning observed crystal morphologies until the next section and focus here on the structure of the three commonly observed surfaces: (001), (210) and (111) surfaces. The (310) surface is also briefly described, being the second most stable of calculated surfaces.

On the (001) surface, there is a slight decrease of the Fe-S distances to $2.21 \AA$ (compared to $2.29 \AA$ in the bulk). $50 \%$ of surface Fe are 5 -coordinated and $50 \%$ of $\mathrm{S}$ are 3 -coordinated. On the surface (210), the Fe-S distances decrease to $2.12 \AA$ and the distances S-S increase to $2.33 \AA$ (compared to $2.18 \AA$ in the bulk). The Fe is 4-coordinated and $\mathrm{S} 2$-coordinated. There is also a 5-coordinated Fe and a 3-coordinated S. On the (111) surface, the Fe atoms are positioned above the $\mathrm{S}$ atoms contrary to the (001) and (210) surfaces. The most external sulfur is bound to $2 \mathrm{Fe}$

Table 3. Surface energies from the literature.

\begin{tabular}{lccc}
\hline Indexes & $\begin{array}{c}\text { Surface energy }\left(\gamma_{\text {hkl }}\right) \\
\left(\mathrm{Jm}^{-2}\right) \text { Force Field }(\mathrm{de} \\
\left.\text { Leeuw et al. } .^{20}\right)\end{array}$ & $\begin{array}{c}\text { DFT Hung et } \\
\text { al. }^{27,28}\end{array}$ & $\begin{array}{c}\text { DFT } \\
\text { Alfonso }^{29}\end{array}$ \\
\hline$(001)$ & 1.23 & $1.06^{28}(001) \mathrm{S}$ & 1.21 \\
$(110)$ & 2.58 & $1.68^{28}(110)-\mathrm{S}$ & 1.79 \\
$(110) \mathrm{fac}$ & & $1.54(\mathrm{mf})^{28}$ & \\
$(111) \mathrm{Fe}$ & 5.09 & & \\
$(111) \mathrm{S}$ & 5.15 & $1.40^{27}(111)-\mathrm{S}$ & 1.49 \\
$(210)$ & - & $1.50^{27}(210)-\mathrm{S}$ & 1.61 \\
\hline
\end{tabular}

note: DFT $=$ Density Functional Theory atoms, at a distance of $2.08 \AA$ and the S-S dimer of $2.25 \AA$ perpendicular to the surface. In the cell of the (310) surface, there are two 4-coordinated $\mathrm{Fe}$, three 5-coordinated $\mathrm{Fe}$, one doubly-bridging $\mathrm{S}$ and six triply-bridging $\mathrm{S}$. The shortest $\mathrm{Fe}-\mathrm{S}$ is $2.12 \AA$, with the doubly-bridging $\mathrm{S}$ species. The distances of surface S-S dimers are slightly higher: $2.21 \AA$, $2.23 \AA$ and $2.34 \AA$.

\section{Discussion}

The crystal structure of pyrite is known and it is easily reproduced using classical and quantum methods. X-ray diffraction is the key method allowing deducing the structure of the unit cell with the atomic positions. The classical calculations are based on experimental data and reproduce the pyrite structure. In the initial chosen structure ${ }^{17}$, the distance parameter of the cubic cell is $\mathrm{a}=5.418 \AA$. After optimization (without imaginary frequencies) using METADISE, the cell parameter is $\mathrm{a}=5.480 \AA$, with a deviation of only $1.1 \%$ from the experimental values. The calculated dielectric constant is 2.31 (against experimental value of 10.9 for the $n$-type pyrite ${ }^{21}$ ) and the elastic constants $\mathrm{C}_{11}=31.99 \times 10^{11} \mathrm{dyn} / \mathrm{cm}^{2}$ (i.e. $320 \mathrm{GPa}$ ), $\mathrm{C}_{12}=5.54 \times 10^{11} \mathrm{dyn} / \mathrm{cm}^{2}$ (i.e. $55 \mathrm{GPa}$ ), and $\mathrm{C}_{44}=10.80 \times 10^{11} \mathrm{dyn} / \mathrm{cm}^{2}$ (i.e. $108 \mathrm{GPa})\left(\mathrm{C}_{11}=38.18, \mathrm{C}_{12}=+3.10, \mathrm{C}_{44}=10.94\right.$, in units of $10^{11} \mathrm{dyn} / \mathrm{cm}^{2}$ from Simmons and $\mathrm{Birch}^{22}$ ). Our results are similar to those given by Sithole et al. ${ }^{30}$

The surfaces have a different role and applications in catalysis / photocatalysis. Pyrite growth, whether on the geological scale or synthesized in the laboratory, depends on external conditions. Under the conditions of low [S] / [Fe] ratio (low sulfur content, high iron content), $\{001\}$ facets grow first and in the opposite case of sulfur-rich environment, the $\{210\}$ and $\{111\}$ facets are favored ${ }^{29,31-33}$. The effect of the sulfur content can be evaluated theoretically using the chemical potential method. Several studies based on quantum calculation techniques apply this method to explain the growth of crystals ${ }^{29,31,34}$. Not only the sulfur content defines the growth direction of the crystal but also the adsorption of species can block the growth of a surface and modify the shape of the crystal. For instance, cubic particles are synthesized when ethanol: $\mathrm{H}_{2} \mathrm{O}$ solutions are used as the solvent ${ }^{5}$, while $\{111\}$ facets are exposed in the presence of $\mathrm{As}^{35}$ or when ethanolamine: $\mathrm{H}_{2} \mathrm{O}$ is used as the solvent ${ }^{36}$. The solubility of pyrite is also one of the factors influencing the growth / dissolution of the crystal and generating sulfuric acid. Oxygen $\left(\mathrm{O}_{2}\right)$ molecules participate, for example, in the dissolution of pyrite ${ }^{37}$ while $\mathrm{Cl}^{-}, \mathrm{SO}_{4}{ }^{2-}$ anions inhibit pyrite oxidation by adsorption ${ }^{14}$. The morphology of pyrite also has an influence on its dissolution and formation of acids. Framboidal forms (aggregates of pyrite spheres similar to a raspberry) are more easily oxidized than euhedral forms (with well-defined facets) ${ }^{38}$.

Kinetic and thermodynamic results obtained in the present study, using classical techniques, indicate that the 
(001) surface is the more stable. Experimentally, the cubic form preferably grows at high Fe content ${ }^{31}$. The (310) and (210) surfaces are also relatively stable and the morphologies generated from them are pyritohedrons.

The morphology of pyrite thus depends on the sulfur content, but also on the surfactants and solvents. For example, chemisorption of oleylamine surfactant favors the growth of the $\{210\}$ surface ${ }^{39}$. A nonionic surfactant (Triton X-100) favors the cubic morphology, that is to say with the stable (100) surface, while polyvinyl pyrrolidone (PVC) favors the octahedral morphology with the $\{111\}$ facets ${ }^{40}$. The cubic morphology is also stabilized by solvents such as ethanol ${ }^{5}$ or ethanolamine ${ }^{36}$.

A characteristic of the $\{111\}$ facet is that it is reactive and the growth in the $<111>$ directions is blocked with As. Fe (II) ions are more exposed than sulfur ions, being a particularity of the surface (111). The reactivity of iron with arsenic is known, which may explain the specificity of the octahedral growth of pyrite in the presence of this element. The reactivity of pyrite with arsenic can be used for the removal of the metal As in solution at controlled $\mathrm{pH}^{41}$. The adsorption of As on the pyrite surfaces is thus an important property for removing the toxic concentrations of the metal in the water.

A high sulfur content also stabilizes the (111) surface. The $a b$ initio calculations with inclusion of the chemical potential in sulfur allow predicting the evolution of the surface energies as a function of temperature and sulfur content ${ }^{33}$. Similarly, ab initio calculations considering the chemical potential show that water favors octahedron formation at low temperature and that the cubic morphology is stabilized at high temperature (above $450 \mathrm{~K})^{31}$. This observation is consistent with the thermodynamic (cubic) growth favored in vacuum and, conversely, with the transformation of the cubic form in the presence of water, leading to the exposition of the (111) surfaces. Figure 6 shows two crystal shapes identical to those synthesized by Yuan et al. ${ }^{36}$. We can even assert that the crystallites have the same morphology but with a different orientation: it is a truncated cube (six $\{100\}$ facets with eight $\{111\}$ facets appearing with a triangular shape at a)

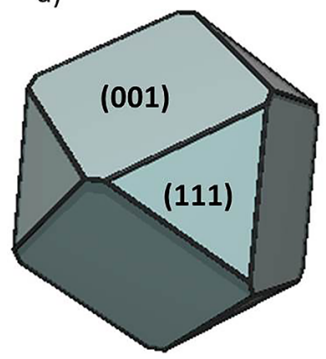

b)

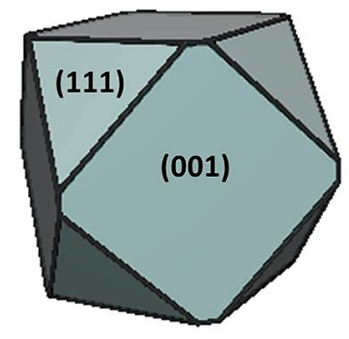

Figure 6. Simulated morphology using the Gibbs-Curie-Wulff construction and surface energies ratio $(111) /(100)=1.2$ with orientations similar to Yuan et al. ${ }^{36)}$. each corner of the cube). The ratio between the (100) and (111) surfaces thus depends on the kinetics and temperature ${ }^{42}$, and the results are consistent with the experimentally observed morphologies. At the geological scale, the phenomena are similar, the growth of pyrite in sulfur-saturated medium favors the non-cubic (i.e., octahedral and pyritohedral) morphologies ${ }^{42}$. Pyrite from the Peruvian mines represents the two cases: with low sulfur content, the pyrite shape is cubic (Fig. 4a), while in the supersaturated solution pyrite is pyritohedral (Fig. 4c).

On the surface of the crystals there are well-defined striations indicating a lateral dimensional growth ${ }^{43}$. Growth directions belong to the $<100>$ family and are visible on $\{100\}$ and $\{210\}$ surfaces. Scanning Electron Microscopy (SEM) enables to magnify the striations made of $\{100\}$ blocks. Fig. 7 represents the pyritohedral morphology with the striations observed by SEM from Fig. 3c. Our observations correspond to the so-called positive pyrite, the usual orientation of the striations in natural pyritohedral pyrite. So far our attempts to encounter the so-called negative pyrite were unsuccessful; the only report of natural pyritohedral negative pyrite is the work published by Endo and Sunagawa ${ }^{25}$. The twin surfaces based on $(2 \pm 10)$ planes have striations along the [001] direction. In order to observe the striations, (hkl) must have at least one index equal to 0 . If $\mathrm{h}=\mathrm{k}=1$, the facets are triangular in the octahedral mineral with no observed striations.

\section{Conclusion}

The geological pyrite presents different morphologies depending on the growth conditions, i.e. the temperature, the $\mathrm{Fe}$ and $\mathrm{S}$ contents of the solution, adsorbed species. The most common forms of pyrite are cubic (with $6\{100\}$ facets), octahedral (with $8\{100\}$ facets), and pyritohedral with 12 distorted pentagonal facets. High sulfur content stabilizes the pyritohedral and octahedral morphologies. Natural pyrite crystals display anisotropies and in particular a striation on some specific facets along the $<001>$ directions. The striations can be attributed to planes with at least one Miller index different from zero. Electron microscopy analysis of natural pyritohedral pyrite enables to point out that exposed surfaces are not (210) surfaces but steps of (001) surfaces, which is the thermodynamic stable surface. No striation is associated to the (111) surface.

The production of synthetic $\mathrm{FeS}_{2}$ is becoming important for industrial applications such as catalysis, gas (photo) detector, removal of pollutants and electronic devices, in which the control of morphologies and particle sizes are determinant factors. Further studies will focus on electronic and magnetic properties of macro- and nano-pyrite using $a b$ initio simulations to better optimize its chemical and physical properties. 

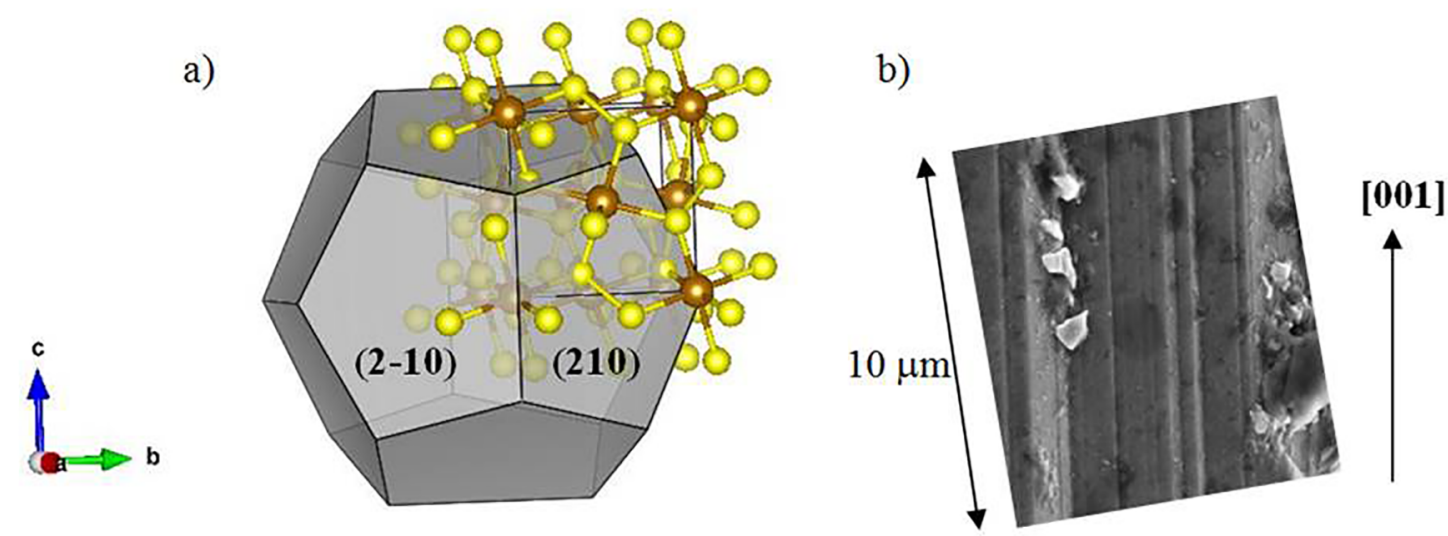

Figure 7. a) Orientation in the pyritohedral pyrite in the unit cell and b) SEM image (FEI Magellan 400) of the (210) surface with striations along the [001] direction.

\section{Acknowledgments}

C. Arrouvel thanks J. Werckmann, Claudine Arrouvel, the Geosciences Museum of USP-São Paulo, the Science and Earth Museum in Urca-RJ for donations of minerals and Alain Prinzhofer for photographing the crystals. J.-G. Eon thanks CNPq for Research grant No 303564/2017-2 and C. Arrouvel thanks CNPq for the postdoctoral fellowship. C. Arrouvel is grateful to Dimat-INMETRO for giving access to the SEM equipment.

\section{References}

1. Baldwin RM, Vinciguerra S. Coal liquefaction catalysis: Iron pyrite and hydrogen sulfide. Fuel. 1983;62(5):498-501.

2. Macpherson HA, Stoldt CR. Iron Pyrite Nanocubes: Size and Shape Considerations for Photovoltaic Application. ACS Nano. 2012;6(10):8940-8949.

3. Golodnitsky D, Peled E. Pyrite as cathode insertion material in rechargeable lithium/composite polymer electrolyte batteries. Electrochimica Acta. 1999;45(1-2):335-350.

4. Ennaoui A, Fiechter S, Pettenkofer C, Alonso-Vante N, Buker $\mathrm{K}$, Bronold $\mathrm{M}$, et al. Iron disulfide for solar energy conversion. Solar Energy Materials and Solar Cells. 1993;29(4):289-370.

5. Liu SL, Li MM, Li S, Li HL, Yan L. Synthesis and adsorption/ photocatalysis performance of pyrite $\mathrm{FeS}_{2}$. Applied Surface Science. 2013;268:213-217.

6. Li W, Döblinger M, Vaneski A, Rogach AL, Jäckel F, Feldmann J. Pyrite nanocrystals: shape-controlled synthesis and tunable optical properties via reversible self-assembly. Journal of Materials Chemistry. 2011;21(44):17946-17952.

7. Hu Z, Zhu ZQ, Cheng FY, Zhang K, Wang JB, Chen CC, et al. Pyrite $\mathrm{FeS}_{2}$ for high-rate and long-life rechargeable sodium batteries. Energy \& Environmental Science. 2015;8(4):13091316.
8. Li LS, Cabán-Acevedo M, Girard SN, Jin S. High-purity iron pyrite $\left(\mathrm{FeS}_{2}\right)$ nanowires as high-capacity nanostructured cathodes for lithium-ion batteries. Nanoscale. 2014;6(4):2112-2118.

9. Mann S, Sparks NHC, Frankel RB, Bazylinski DA, Jannasch HW. Biomineralization of Ferrimagnetic Greigite $\left(\mathrm{Fe}_{3} \mathrm{~S}_{4}\right)$ and Iron Pyrite $\left(\mathrm{FeS}_{2}\right)$ in a Magnetotactic Bacterium. Nature. 1990;343(6255):258-261.

10. Bazylinski DA, Garratt-Reed AJ, Frankel RB. Electron microscopic studies of magnetosomes in magnetotactic bacteria. Microscopy Research and Technique. 1994;27(5):389-401.

11. Bebié J, Schoonen MAA. Pyrite and phosphate in anoxia and an origin-of-life hypothesis. Earth and Planetary Science Letters. 1999;171(1):1-5.

12. Kundell FA. A suggested pioneer organism for the Wachtershauser origin of life hypothesis. Origins of Life and Evolution of Biospheres. 2011;41(2):175-198.

13. de Mello JWV, Duarte HA, Ladeira ACQ. Origem e Controle do Fenômeno Drenagem Ácida de Mina. Cadernos Temáticos de Química Nova na Escola. 2014;8:24-29.

14. Chandra AP, Gerson AR. Redox potential (Eh) and anion effects of pyrite $\left(\mathrm{FeS}_{2}\right)$ leaching at $\mathrm{pH}$ 1. Geochimica Et Cosmochimica Acta. 2011;75(22):6893-6911.

15. Bryan CG, Watkin EL, McCredden TJ, Wong ZR, Harrison STL, Kaksonen $\mathrm{AH}$. The use of pyrite as a source of lixiviant in the bioleaching of electronic waste. Hydrometallurgy. 2015;152:33-43.

16. Born M, Huang K, eds. Dynamical Theory of Crystal Lattices. New York: Oxford University Press; 1954.

17. Brostigen G, Kjekshus A. Redetermined Crystal Structure of $\mathrm{FeS}_{2}$ (Pyrite). Acta Chemica Scandinavica. 1969;23(6):2186-2188.

18. Watson GW, Kelsey ET, de Leeuw NH, Harris DJ, Parker SC. Atomistic simulation of dislocations, surfaces and interfaces in MgO. Journal of the Chemical Society, Faraday Transactions. 1996;92(3):433-438.

19. Tasker PW. The surface energies, surface tensions and surface structure of the alkali halide crystals. Philosophical Magazine A. 1979;39(2):119-136. 
20. de Leeuw NH, Parker SC, Sithole HM, Ngoepe PE. Modeling the Surface Structure and Rreactivity of Pyrite: Introducing a Potential Model for FeS ${ }_{2}$. Journal of Physical Chemistry B. 2000;104(33):79697976.

21. Husk DE, Seehra MS. Dielectric constant of iron pyrite $\left(\mathrm{FeS}_{2}\right)$. Solid State Communications. 1978;27(11):1147-1148.

22. Simmons G, Birch F. Elastic Constants of Pyrite. Journal of Applied Physics. 1963;34(9):2736-2738.

23. Woensdregt CF. Hartman-Perdok theory: influence of crystal structure and crystalline interface on crystal growth. Faraday Discussions. 1993;95:97-107.

24. Wulff G. Zur Frage der Geschwindigkeit des Wachstums und der Auflösung der Krystallflagen. Zeitschrift Fur Kristallographie. 1901;34(5/6):449-530

25. Endo Y, Sunagawa I. Positive and Negative Striations in pyrite. American Mineralogist. 1973;58(9-10):930-935.

26. Alonso-Azcárate J, Rodas M, Fernández-Diaz L, Bottrell SH, Mas Mayoral JR, López-Andrés S. Causes of variation in crystal morphology in metamorphogenic pyrite deposits of the Cameros Basin (N Spain). Geological Journal. 2001;36(2):159-170.

27. Hung A, Muscat J, Yarovsky I, Russo SP. Density-functional theory studies of pyrite $\mathrm{FeS}_{2}(111)$ and (210) surfaces. Surface Science. 2002;520(1-2):111-119.

28. Hung A, Muscat J, Yarovsky I, Russo SP. Density-functional theory studies of pyrite $\mathrm{FeS}_{2}(100)$ and (110) surfaces. Surface Science. 2002;513(3):511-524.

29. Alfonso DR. Computational Investigation of FeS, Surfaces and Prediction of Effects of Sulfur Environment on Stabilities. Journal of Physical Chemistry C. 2010;114(19):89718980 .

30. Sithole HM, Ngoepe PE, Wright K. Atomistic simulation of the structure and elastic properties of pyrite $\left(\mathrm{FeS}_{2}\right)$ as a function of pressure. Physics and Chemistry of Minerals. 2003;30(10):615-619.

31. Barnard AS, Russo SP. Modelling nanoscale $\mathrm{FeS}_{2}$ formation in sulfur rich conditions. Journal of Materials Chemistry. 2009;19(21):3389-3394.
32. Liu S, Wu J, Yu P, Ding Q, Zhou Z, Li H, et al. Phasepure iron pyrite nanocrystals for low-cost photodetectors. Nanoscale Research Letters. 2014;9:549.

33. Zhang YN, Law M, Wu RQ. Atomistic Modeling of Sulfur Vacancy Diffusion Near Iron Pyrite Surfaces. Journal of Physical Chemistry C. 2015;119(44):24859-24864.

34. Arrouvel C, Toulhoat H, Breysse M, Raybaud P. Effects of $\mathrm{P}_{\mathrm{H} 2 \mathrm{O}}, \mathrm{P}_{\mathrm{H} 2 \mathrm{~S}}, \mathrm{P}_{\mathrm{H} 2}$ on the surface properties of anatase- $\mathrm{TiO}_{2}$ and $\gamma-\mathrm{Al}_{2} \mathrm{O}_{3}$ : a DFT study. Journal of Catalysis. 2004;226(2):260272 .

35. Hayashida S, Muta K. Relation of trace-element content and crystal form in pyrite. Journal of the Mining Institute of Kyushu. 1952;20:233-238.

36. Yuan B, Luan W, Tu ST, Wu J. One-step synthesis of pure pyrite $\mathrm{FeS}_{2}$ with different morphologies in water. New Journal of Chemistry. 2015;39(5):3571-3577.

37. Moses CO, Nordstrom DK, Herman JS, Mills AL. Aqueous pyrite oxidation by dissolved oxygen and by ferric iron. Geochimica Et Cosmochimica Acta. 1987;51(6):1561-1571.

38. Weisener CG, Weber PA. Preferential oxidation of pyrite as a function of morphology and relict texture. New Zealand Journal of Geology and Geophysics. 2010;53(2-3):167-176.

39. Zhu L, Richardson BJ, Yu Q. Anisotropic Growth of Iron Pyrite $\mathrm{FeS}_{2}$ Nanocrystals via Oriented Attachment. Chemistry of Materials. 2015;27(9):3516-3525.

40. Wang DW, Wang QH, Wang TM. Controlled growth of pyrite $\mathrm{FeS}_{2}$ crystallites by a facile surfactant-assisted solvothermal method. Crystal Engineering Communications. 2010;12(3):755-761.

41. Kim EJ, Batchelor B. Synthesis and characterization of pyrite $\left(\mathrm{FeS}_{2}\right)$ using microwave irradiation. Materials Research Bulletin. 2009;44(7):1553-1558.

42. Murowchick JB, Barnes HL. Effects of temperature and degree of supersaturation on pyrite morphology. American Mineralogist. 1987;72(11-12):1241-1250.

43. Yamada S, Nanjo J, Nomura S, Hara S. Morphology of iron pyrite crystals. Journal of Crystal Growth. 1979;46(1):1014. 